\title{
A comparison of secondary schools students' levels of conception of qualitative and quantitative inorganic analysis
}

\author{
${ }^{1}$ Francis A Adesoji and ${ }^{2}$ Nathaniel Ayodeji Omilani \\ ${ }^{1}$ Department of Teacher Education, Faculty of Education, University of Ibadan, \\ Ibadan, Oyo State, Nigeria \\ ${ }^{2}$ Integrated Science Department, Federal College of Education, Oshiele, Abeokuta, \\ Ogun state, Nigeria
}

\begin{abstract}
This study constructed a two tier multiple choice questions to assess the levels of conception of students in qualitative and quantitative inorganic analysis. The study is an ex-post facto. The population consisted of all S.S.S.3 students in Ibadan south-west local government area of Oyo state, Nigeria. The sample is made of five public and five private schools selected from the local government and a total of 500 students attempted the test. The data were analysed using Analysis Of Variance and Tukey to ascertain the direction of difference in the three levels of conception. Results showed that there was a significant difference in the three levels of conception by the secondary school students in Chemistry. More students were discovered to be at the macroscopic level which was the farthest from the meaningful learning of the concepts. Furthermore, very few were at the submicroscopic and symbolic levels of conception which was the closest to the meaning of those concepts in qualitative and quantitative analysis. Recommendations based on the importance of proper and high level of conception were made.
\end{abstract}

\section{INTRODUCTION}

Conceptual change from non-scientific idea of phenomenon in nature to scientific idea is the central focus of science education. Learning cannot be said to have taken place in a science classroom until the students' conception is in line with the scientific idea being expounded. This is necessary because for most of the concepts being taught in science, students already have a preconception or alternative conception which can hinder the actual conception change which is the aim of every science instruction (Vosnialdou and Inannides 1998).Chemistry is very important because it gives students the understanding of how the world works. However, most students either before or after school instruction cannot develop appropriate structure of chemistry concepts because of the abstract nature of the subject (Chiu, 2005). All concepts in Chemistry can be learnt meaningfully when the students have attained conceptual change at three levels of conception that exist in chemistry. These levels of conceptions are the macroscopic, submicroscopic and symbolic levels. With the current explosion in scientific knowledge most especially Chemistry emphasis is now placed on the symbolic level of conception because it is the closest to meaningful learning and students should be able to link the three levels of conception (Aksella, 2005). Chemistry occupies a central position among all science subjects. It is a core subject for Medical science, Textile science, Agriculture science, Synthetic industry, Printing technology, Pharmacy, Chemical technology (Jegede, 2007). Therefore, the essence of appropriate conception of concepts related to Chemistry is of a very great significance because it is very important to science and technology.

Conception that is most appropriate is the one that the learner links the three levels of meaning in Chemistry and can appropriately relate them in the scientific way. Chiu (2005) opines that students need not to only understand symbols, terminologies, and theories used in learning chemical concepts, but they also need to transform instructional language or material teachers use in the Chemistry classroom into meaningful representation. The abstract nature of Chemistry has made it difficult for students to conceptualise the important concepts. Gabel and Bunce (1994) found out that students' conception of matter as a collection is too rudimentary. Novick and Nussbaum (1978) found out that a significant portion 
of $8^{\text {th }}$ grade Israeli students' failed to internalize important aspect of particle model of matter. Schmdith (1995) found that $11^{\text {th }}$ to $13^{\text {th }}$ graders did not have well developed conception about the differences between acid and base. Abraham, Williamson and Westbook (1994) found out the difficulty students have in developing the concept of chemical and physical change, most of the subjects of their research considered candle burning to be a physical change and dissolution of sugar to be a chemical change.

There are enough evidences to show that laboratory work is the only effective and efficient teaching strategy of attaining scientific goals which is actually a conceptual change (Okebukola,1986\&Tobin1990).Wood (2006) reported the impact of Johnstone certificate of sixth year study (CSYS) which one third of the evaluation is allocated to practical work and project. The thinking skills of students of chemistry who were part of CSYS were fostered and they had positive attitude to the subject. Practical Chemistry without any doubt makes students to attain a high level of conception which results into meaningful learning. Unfortunately, the performance of students in Chemistry practical which is suppose to enhance meaningful learning is very poor in Nigeria. In fact Akinleye (1987) lamented that students' failure in Chemistry examination can be traced to their poor performance in the practical. Njoku (2005) observed that the most difficult aspect in the SSCE practical is the last part of the question that requires high level of conception of the underlying principle responsible for the physical changes that excite students at the macroscopic level of conception. According to Njoku (2005) an examination of Chemistry practical in Nigerian secondary schools consists of three major parts namely:

a. Quantitative analysis involving acid base titrations and computation of unknown variables using data generated.

b. Qualitative analysis involving the identification of given chemical substances through the analysis of their constituent ions and/or functional groups.

c. The last aspect is the most crucial because it involves no practical but requires a cognitive understanding of the basic principles underlying quantitative and qualitative analysis. It usually involves theoretical task drawn from question contents of the first two aspects.

Qualitative and quantitative analysis as a practical activity was designed not just to fulfill the demands of the Chemistry curriculum which insists that it should be taught as an experimental science, rather, it offers students a feel of scientific phenomena and foster conceptual understanding .

Conception in qualitative and quantitative analysis exists at three levels viz:

\section{MACROSCOPIC LEVEL}

Onwu and Randall (2006) are of the opinion that students' interest in Chemistry is easily captured at the macroscopic level as this level of representation describes the bulk of the properties of tangible and visible phenomena in everyday experiences of learners. This is brought about when such learners observe the change in the properties of matter e.g. colour changes, $\mathrm{pH}$ of aqueous solution, formation of gases, precipitates in chemical reactions and solubility of residue and precipitate.

\section{SUBMICROSCOPIC LEVEL}

Beyond the macroscopic level of representation we have a fuller representation which is submicroscopic. The level provides explanation at the particule level in which matter is described as being composed of atom, molecules and ions.

\section{SYMBOLIC LEVEL}

The final level of representation is the symbolic representation. This involves the use of chemical symbols, formulas and equation as well as molecular structure, drawing diagram, model and computer animation to symbolize matter.

In qualitative analysis for example, observation and recording of effervescence of a colourless and odourless gas that turns lime water milky and changes the blue litmus to red during qualitative analysis is associated with macroscopic level. Going further to provide explanation that it is the carbonate salt that decomposes on heating to give colourless and odourless $\mathrm{CO}_{2}$ gas is at the submicroscopic level.

Finally, the ability to write the correct equation for decomposition reaction is at the symbolic level of conceptions.

Research has shown that students have great difficulty relating what they have learnt in the macroscopic level to the submicroscopic and 
symbolic levels of conception (Onwu and Randall, 2006).

Most of the researchers are of the opinion that meaningful conception is ontological. It takes place within. Constructivism is a learning theory that encourages development of metacognitive strategies (Gunstone, 1994).Learners are encouraged to learn meaningfully so that the retrieval of knowledge during testing will not be a difficult task.

Research on science learning has shown that the concepts that comprise a subject matter have a relational structure that influences their order of acquisition. Relational structures are referred to as advance organizers by Ausubel cited by Novak (1997). For example, the understanding of valency is a relational structure to writing chemical formulae and kinetic theory of gases is the relational structure that will facilitate the assimilation of all the gas laws.

Therefore, any curriculum that will enhance conceptual change must be appropriately sequenced. Teaching needs to be informed through preservice and inservice training which must put into consideration the preconception of students and teachers when instructions are being designed (Horton, 2007).

To facilitate conceptual change during instruction teachers should ensure that students are aware of their implicit representation as well as of the beliefs and presupposition that can constrain them from adequate conception. Teachers must also provide meaningful explanation and be motivated to change the students' implicit representation, beliefs and presupposition.

The performance of students in Chemistry practical is generally poor at the SSCE level. This poor performance has been traced to factors such as lack of facilities for practical in schools. Apart from this, it is believed that the students' inability to understand symbols, terminologies and theories used in learning chemical concepts that are related to qualitative and quantitative inorganic analysis has contributed to the general poor performance.

Few students with good performance do so by rote memorization of facts without transforming the language and materials teachers use in Chemistry practical into meaningful representations. The focus of this study therefore is to find out students' levels of meaningful representation of facts related to qualitative and quantitative analysis. It is expedient at this point that beyond the teaching methodology, it appropriate to examine the conceptions of students in quantitative and qualitative analysis and the implication to classroom situation.

\section{Variables of the study}

Independent variable in this study refers to the knowledge provided in qualitative and qualitative analysis by teachers using the same method of instruction

Dependent variable in this study refers to students' level of conception of concepts in qualitative and quantity analysis, which is at three levels:

i. Macroscopic

ii. Submiscrospic

iii. Symbolic

This was measured using two tier achievement test.

\section{Research Questions}

1. What are the levels of secondary school students' conception in qualitative and quantitative analysis?

2. Are students' conceptions in line with scientific ideas?

\section{HYPOTHESES}

1. There is no significant difference in the students' conception at the three levels of conceptions.

\section{METHODOLOGY}

The study adopted a descriptive survey design of the ex-post facto type. The reason is that the study is an assessment of students' conception. The ex-post facto research describes the status of a phenomenon at a particular time. Assessment in education is used to describe students' progress toward educational goals. Best and Kahn (1993) opine that assessment, evaluation and descriptive research are not mutually exclusive. The level of conception is a measure of achievement through a two tier multiple choice test.

Instrument: The instrument used was a Qualitative and Quantitative Analysis Two Tier Multiple Choice Question. The instrument was used to diagnose students' misconceptions and also to identify the levels of conception. The first tier of the items consisted of content questions that have to do with macroscopic level of conception while the second tier related to the submicroscopic and symbolic levels. The second tier also required for the underlying reasons for the option selected in the first tier. The 
items which were 20 in number covered all the aspects of the qualitative and quantitative inorganic analysis. The distracters were obtained from common misconception of inorganic reactions found in the literature.

Population and Sample : The target population was SSS III science students and teachers from Ibadan Southwest Local government private and public secondary schools. The sample consisted of 500 students, selected from five public schools and five private schools in the local government. The selection was done without gender bias, thus a proportionate sampling technique was adopted.

S.S.S III students were selected because they are ready to take SSCE Chemistry practical examination which involves qualitative and quantitative analysis, and it is very certain that they have covered that aspect of the syllabus.

Validity and Reliability of Instrument: The two tier multiple test was validated by four Chemistry teachers in schools and three postgraduate Chemistry students.

The reliability of the test was determined using the Kuder Richardson formula 20 and the value obtained for students is 0.8112
The Procedure for Data Collection :The researcher personally administered the two tier multiple choice questions to the students. The researcher collected the answered two multiple choice immediately before leaving the school. This was done during normal class period.

Scoring of the Two tier multiple choice question: The students' responses to the two tier multiple choice question was scored 2 marks. One mark was for the content related questions and one mark for the reason. No mark was awarded if the response to the first tiers was wrong. The students who got 15 items out of 20 items correctly or above were classified into the symbolic level of conceptions. Those who got out of 14 to 10 items correctly were classified into the sub-microscopic level of conception while those who got less than 10 items correctly were placed at the macroscopic level of conception. The test was scored manually.

Analysis and presentation of data: The data for the study were analyzed using one-way Analysis of Variance both the one way and two way to locate the level of significance.

What are the levels of secondary school
students' conception in qualitative and
quantitative analysis?

TABLE 1:DESCRIPTIVE STATISTICS FOR TOTAL CONCEPTION

\begin{tabular}{|c|c|c|c|c|c|c|c|c|}
\hline & \multirow[b]{2}{*}{$\mathrm{N}$} & \multirow[b]{2}{*}{ Mean } & \multirow{2}{*}{$\begin{array}{l}\text { Std. } \\
\text { Deviation }\end{array}$} & \multirow{2}{*}{$\begin{array}{l}\text { Std. } \\
\text { Error }\end{array}$} & \multicolumn{2}{|c|}{$\begin{array}{l}95 \% \text { Confidence Interval } \\
\text { for Mean }\end{array}$} & \multirow[b]{2}{*}{ Minimum } & \multirow[b]{2}{*}{ Maximum } \\
\hline & & & & & Lower Bound & Upper Bound & & \\
\hline Macroscopic level & 293 & 13.70 & 5.168 & .302 & 13.11 & 14.30 & 2 & 22 \\
\hline Submicroscopic level & 145 & 26.11 & 2.038 & .169 & 25.78 & 26.44 & 23 & 29 \\
\hline Symbolic level & 62 & 32.05 & 2.068 & .263 & 31.52 & 32.57 & 30 & 40 \\
\hline Total & 500 & 19.58 & 8.327 & .372 & 18.84 & 20.31 & 2 & 40 \\
\hline
\end{tabular}

From Table 1, it can be observed that there are only 62 students at the symbolic level of conception which about $12.4 \%$ of the students in the study. There are 145 students at the submicroscopic level of conception which is $29 \%$ of the sample. Students are mostly at the macroscopic levels of conception 293 which is about $63.6 \%$. The result showed that the majority of the students are at the macroscopic level of conception which is very far from the meaningful learning of the concepts related to qualitative and quantitative analysis. The students' thinking at the submicroscopic and symbolic levels of conceptions consist of misconception. For example, the second tier of item 2 in the instrument seeks to check whether students know the reason why zinc, aluminium and lead ions are soluble in excess sodium hydroxide. $82 \%$ of the students chose option 3 , that is, the sodium hydroxide is in excess. Their thinking is based on a qualitative idea that the more the solvent the higher the solubility of the solute whereas the right option is 2, that is, the hydroxide of the ions are amphoteric. The hydroxide formed by the three ions in drops has the ability to react with excess sodium hydroxide to form a complex. This is 
Am. J. Sci. Ind. Res., 2012, 3(2): 56-61

what Onwu and Randall (2007) referred to as the use

of macroscopic properties to infer particle properties.

TABLE 2:ANOVA FOR THE THREE LEVELS OF CONCEPTION

\begin{tabular}{|l|l|l|l|l|l|}
\hline Total Conception & Sum of Squares & Df & Mean Square & F & Sig. \\
\hline Between Groups & 25941.855 & 2 & 12970.928 & 744.555 & .000 \\
\hline Within Groups & 8658.257 & 497 & 17.421 & & \\
\hline Total & 34600.112 & 499 & & & \\
\hline
\end{tabular}

In Table 2, there is a significant difference in the three levels of conceptions in qualitative inorganic conceptions. This finding led to the rejection of the analysis $\left(F_{2,497}=744.5 p<0.05\right)$. This means that there only hypothesis because the $p$ value is 0.000 was a significant difference in the three levels of

Table 3 :TUKEY HSD MULTIPLE COMPARISON OF THE THREE LEVELS OF CONCEPTION

\begin{tabular}{|c|c|c|c|c|c|c|}
\hline \multirow[b]{2}{*}{$\begin{array}{l}\text { (I) Conception } \\
\text { level }\end{array}$} & \multirow[b]{2}{*}{ (J) Conception level } & \multirow[b]{2}{*}{$\begin{array}{l}\text { Mean } \\
(I-J)\end{array}$} & \multirow[b]{2}{*}{ Std. Error } & \multirow[b]{2}{*}{ Sig. } & \multicolumn{2}{|c|}{ 95\% Confidence Interval } \\
\hline & & & & & Lower Bound & $\begin{array}{l}\text { Upper } \\
\text { Bound }\end{array}$ \\
\hline \multirow{2}{*}{$\begin{array}{l}\text { Macroscopic } \\
\text { level }\end{array}$} & Semi Microscopic level & $-12.240^{\star}$ & .406 & .000 & -13.20 & -11.28 \\
\hline & Symbolic level & $-17.621^{\star}$ & .554 & .000 & -18.92 & -16.32 \\
\hline \multirow{2}{*}{$\begin{array}{l}\text { Submicroscopi } \\
\text { c level }\end{array}$} & Macroscopic level & $12.240^{\star}$ & .406 & .000 & 11.28 & 13.20 \\
\hline & Symbolic level & -5.381 & .598 & .000 & -6.79 & -3.97 \\
\hline \multirow[t]{2}{*}{ Symbolic level } & Macroscopic level & $17.621^{\star}$ & .554 & .000 & 16.32 & 18.92 \\
\hline & Semi Microscopic level & $5.381^{\circ}$ & .598 & .000 & 3.97 & 6.79 \\
\hline
\end{tabular}

Table 3: Tukey HSD Multiple Comparison of The Three Levels Of Conception In order to ascertain the direction of difference in the three levels of conception, Tukey post Hoc comparison test was carried out and the result is presented in Table 3 above. The Table shows that the least mean difference occurred between the submicroscopic and symbolic levels of conception (5.38) and it is significant at 0.05 .This is followed by the mean difference between macroscopic and submicroscopic levels of conception (12.24), also significant at $p<0.05$. The highest level of significant mean difference occurred between symbolic and macroscopic level (17.62) $p<0.05$.

\section{DISCUSSION AND CONCLUSION}

Results revealed that there is a significant difference in the three levels of conception. What this means is that the level of conception of students is not perfectly in line with the scientific idea of the concepts related to qualitative and quantitative inorganic analysis. Most of the students are in the macroscopic level of understanding, which is the farthest from meaningful learning and very few are at the symbolic level of conception which is the closest to meaningful learning. The gap between the macroscopic level of conception is even very high. This also means that when students learn Chemistry practical only very few of them have the inquisitiveness to ask the reason for the visible changes that occur. This result is in line with that of Chandrasegaran et al (2007) that students are always confused between macroscopic and submicroscopic representations, and have the tendency to extrapolate bulk macroscopic properties of substances to the submicroscopic level, and have limited understanding of the symbolic representational system. It is also in line with Onwu and Randall (2006) which found out that students are always inconsistent their reasoning about the particulate nature of matter because they have no appropriate representational models. The result is also in line with that of Stamovlasis et al (2005), which discovered that students have difficulty in questions that have to do with conception in Chemistry compared to the ones that have to do with algorithm. 
Majority of the students were unable to score the second tier which is related to submicroscopic and symbolic level of conception and without a meaningful learning of qualitative and quantitative analysis it is impossible to attain such a very high order of thinking, which recognizes the principles responsible for all the physical changes in Chemistry. This is also a reflection of the fact that students' conception is not in line with the scientific ideas of qualitative and quantitative analysis. There is a gap between the macroscopic level of conception and symbolic level. This gap could be traced to teacher not asking question on the reason for the physical changes that occur at the macroscopic level. It is strongly recommended that teachers explain the causes of the changes that excite the students at the macroscopic level. The study of conception and misconception in Chemistry should be integrated in pre-service teacher training. This should also go for other science subjects.

There should be improved evaluation procedures, like the two tier multiple choice question that discourages memorization of facts and principles, and which places emphasis on higher cognitive processes and higher levels of conceptions.

In-service teachers should be trained on how to handle misconception even during instruction.

Effective teaching and learning of Chemistry practical does not depend only on the availability of apparatus and reagent, it also depend on proper conception, which plays the most crucial role in ensuring that the goal of Chemistry practical is perfectly achieved. As the child interacts with the reagents and apparatus in the laboratory there must be an appropriate link between the observation that excite and the chemical theories that support them.

\section{REFERENCES}

Akinleye B.A 1987 Why our students failed practical chemistry examination (volumetric analysis) at the ordinary level. Journal of Science Teacher Association of Nigeria 25(2)22-31

Chandrasegaran A.L., Treague D.F. and Mocerno M. 2007 The development of a two-tier multiple choice diagnostic instrument of evaluating secondary school students' ability to describe and explain chemical reaction using multiple levels of representation Chemistry education research and practices 8.3:283307.

Chiu M H 2005 A National survey of students' conception in chemistry in Taiwan. Chemical Education International 6 (1)
Gabel,D.L\& Bunce D M (1994).Research on Chemistry.In D.Gabel (Ed), Handbook of research on science Teaching and Learning (pp 301-316), New York Macmillian

Horton C. 2007 Student Alternative conceptions in Chemistry. California,Journal of Science education $7(2)$

Jegede S.A (2007) Students' anxiety towards the learning of Chemistry in some Nigerian secondary School Educational research and review vol 2(7) pp193-197

Njoku Z.C 2007 Comparison of students' achievement in the three categories of questions in SSCE practical Chemistry examination, Journal of science teachers association of Nigeria. Vol 42, Number 1 \& 7 pg 67-73.

Novick S.\& Nussbaum .J 1978 Junior high school students' understanding of the particulate nature of matter :an interview study .Science Education, 62(3) 273-281

Okebukola P.A.O 2006 Students' performance in pratical:A study of some related factors.24 2 119-126.Journal of research in science teaching.

Onwu G.O.M. and Randall E. 2006 some aspects of student understanding of representational model of the particular nature of matters in Chemistry in three different countries. Chemistry education Research and practice. 7.4:226-236.

Schmidit,H-J 1995 Applying the concept of conjugation to the Bronsted theory of acid-base reactions by senior high schools students from Germany. International Journal of science education, 17(6),733-742

Stamovlassis, D. Tsaparlis, G., Charalambos K. Papaoi Kronomou and Zarotiadouf 2005 Conceptual Understanding versus algorithmic problem solving. Further evidence from a national Chemistry examination Chemistry education research and practice.

Tobin K.G 1990 Research on science laboratory activities. In pursuit of better questions and answers to improve learning .School science and Mathematics.

Vasniadou S. and loannides 1998. From conceptual development to science education: A psychological point of view. International Journal of Science Education. 20.2:1213-1230.

Vosniddou.S 1999 conceptual change research : state of the art and future directions in Schnotz.W,Vosniadu.S\&Carretero (eds),New perspective on the conceptual change 3-13.Amster Pergamon.

Wood.C (2006) The development of creative problem solving in chemistry.Chemistry Education Research and Practice 7(2) 96-113. 